\title{
Improving eye health using a child-to-child approach in Bariadi, Tanzania
}

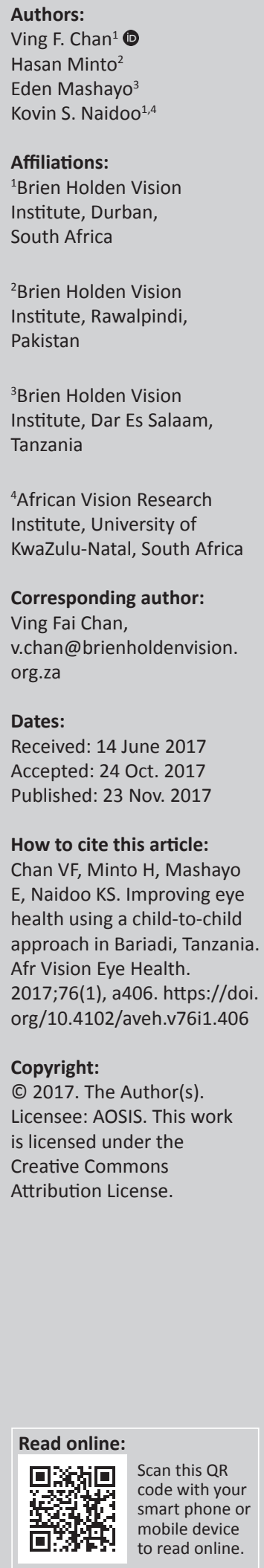

Purpose: Vision Champions (VC) are children trained to perform simple eye health screening and share eye health messages among their community. Our objectives were to assess the ability of VC in identifying and referring children and the community with refractive error and obvious ocular disease and to assess the change in knowledge and practice of eye healthseeking behaviour of the community 3 months after the introduction of the Vision Champion Programme.

Methods: We purposively sampled 600 households and interviewed 1051 participants in two phases with a close-ended questionnaire. The numbers of children screened, referred by the VC and those who attended the Vision Centre were recorded. The percentage of people who answered the questions correctly were compared between Phase 1 (P1) and Phase 2 (P2).

Results: The VC shared their eye health messages with 6311 people, screened 7575 people's vision and referred 2433 people for further care. The community were more aware that using eye ointment not prescribed by doctors ( 1 1 $=58.96 \%$ vs. $\mathrm{P} 2=72.75 \%$ ) can lead to blindness. Participants were more aware that they should not administer eye drops in stock (P1 $=44.18 \%$ vs. $\mathrm{P} 2=61.37 \%)$ or received from a friend or relative $(\mathrm{P} 1=53.23 \%$ vs. $\mathrm{P} 2=72.35 \%)$ if their eyes are red and painful.

Conclusion: Children have the potential to effectively share eye health messages and conduct simple vision screening for their families and peers. Efforts are needed to sensitise the community to improve the referral or follow-up rate.

\section{Introduction}

Vision correction in children poses specific challenges which are different from the challenges of vision correction in adults. Children are born with an immature visual system and, for normal visual development to occur, they need clear and focused images to be transmitted to their higher visual centres. Failure of normal visual development, termed amblyopia, cannot be corrected in adult life; therefore, treating reduced vision in children is a matter of urgency. While there were no data available regarding the prevalence and causes of eye disease in Bariadi District, Social for International Development reported that the eye conditions that affect children of 0-15 years old in Tanzania are refractive error, low vision, corneal scarring and ophthalmia neonatorum. ${ }^{1}$ In the age group of 5-15 years, non-correction of refractive error and other eye conditions is because of several factors, including the lack of vision screening and limited access to available and affordable refractive corrections. Other factors include the lack of awareness and recognition of the problem at personal and family levels, as well as at community and public health levels. ${ }^{2}$ Furthermore, human resources are scarce in developing countries and innovative approaches are needed to identify people with eye conditions early and refer them for management. Appropriate solutions are therefore needed, which can offer an effective mechanism for service delivery.

Bariadi ward is located at the Bariadi District, Simiyu region of Tanzania. It is a rural town where $84 \%$ of the households are engaged in agricultural activities. The mean household size was 6.1 members per household. The primary school general enrolment is as high as $96 \%$ for boys and $91 \%$ for girls. About $27 \%$ of the population use health care facilities available, with the majority of them seeking care from the governmental hospital and pharmacy.

At the primary level, eye care interventions in community settings broadly focus on prevention through the promotion of eye health by spreading eye health information and overcoming the barriers that prevent the uptake of eye care services. Several studies have shown that barriers to the uptake of eye care services according to the recipients include access, bad outcomes, costs, 
distance, equity and remoteness. $3,4,5,6,7,8,9,10,11,12$ These barriers are compounded when remote populations have to overcome significant language barriers. ${ }^{13,14}$ In addition, the recipients' world view and the concept of illness and health are usually significantly different from that of the health care providers. ${ }^{14}$ Cultural differences and communication barriers between the providers and receivers greatly hindered access to the uptake of health care services ${ }^{15}$ and treatment. ${ }^{16}$

Any community member appropriately trained in eye health can render services to their respective communities to overcome the above-mentioned barriers. Their contribution is multi-faceted. They identify patients with eye care issues and motivate them to seek professional advice, interpret and communicate the health care provider's advice to the patient and finally help the health provider to understand the perspectives of the local population. Children can be good ambassadors in this regard because they have a good knowledge of their neighbourhood, are accepted in the community and often might be the only people to receive formal education in their families.

Evidence shows that indigenous eye care workers helped to reduce barriers and helped visiting health providers and specialists understand and appreciate the receiver's world view, thereby improving mutual respect for each other. ${ }^{17} \mathrm{~A}$ child is not only a positive agent to their peers; they also have the potential to influence their family and community in improving their health-seeking behaviour. Children as Vision Champions offer an innovative solution for the reduction in vision impairment, especially in developing communities that are still lacking in resources.

The Vision Champion: Children as agents of change programme is a pilot project to test the child-to-child approach in spreading eye health messages and conducting simple vision screening in Tanzania. With the data collected, the investigators will make modifications, based on the scientific evidence, to the Vision Champion Programme to ensure that it is acceptable, applicable and replicable to the local context. The revised version will be recommended to the Ministry of Health and Ministry of Education for their integration to the primary health care system.

The objectives of the study were firstly to assess the ability of Vision Champions in identifying and referring children and others in their community with refractive error and obvious ocular disease, and secondly to assess the change in knowledge, attitude and practice of eye health-seeking behaviour of the community 3 months after the introduction of the Vision Champion Programme. With the data collected, the investigators were able to make modifications based on the scientific evidence to the Vision Champion initiative to ensure that it is acceptable, applicable and replicable in the local context. The revised version will be recommended to the Ministry of Health and Ministry of Education for their integration to the primary health care system.

\section{Research methods and design Study design}

This is a quantitative study using a prospective longitudinal design.

\section{Sampling}

We purposively selected and trained 120 children (who were called Vision Champions) from 10 clusters in Bariadi ward, Bariadi District, Tanzania. The children were selected in consultation with the teachers in the 10 schools. Vision Champions were children from Senior Primary (Standard 5 or 6), aged 11 and 12 years old, who were confident with good communication skills (as judged by the class teacher) and were willing to voluntarily participate in the study. Learners in their last years of primary school have the required literacy skills and the ability to understand and implement the instructions of the programme.

Ten schools were randomly chosen from Bariadi ward and 12 Vision Champions per school were selected for basic eye health screening training and health promotion strategies. Each Vision Champion was trained to screen children and family or extended family living at his or her address as well as five adjacent households. In Bariadi, these households were usually part of the Vision Champion's immediate family members. In addition, the Vision Champion informed the adults and children in all five households about the key eye health conditions affecting the community.

Twenty teachers (two per school) were chosen to assist in mentoring and monitoring the students and also to assist with accurate record-keeping. The selection was made by the head teacher from a group of volunteers and was based on the teachers' knowledge of a learner's ability to communicate and serve such a role. The teachers were ideally the health coordinators in their respective schools. If there was no health coordinator in the school, a suitable teacher was appointed by the head teacher for this particular project.

\section{Methods}

Each Vision Champion received a one-day training course (didactic sessions, demonstration and role play) and an eye screening kit which included a modified chart for vision screening and eye health materials. The modified chart consisted of a Snellen visual acuity (VA) cut-off of 6/12. A person was referred if his or her monocular vision was less than VA 6/12. The five main eye conditions that were screened by the Vision Champions include red eyes, teary or watery eyes or eyes with discharge, white eyes (corneal or pupil), visible squint and reduced vision.

The small pamphlet's eye health messages included:

- eye and facial cleanliness to prevent eye infections

- nutritious food for healthy eyes

- prevention of eye trauma or injury 
- information about squints and the need for immediate referral

- information about reduced vision and the need for immediate referral

- information about cataracts.

Three-tier coupons were used to track the referrals of the Vision Champions. Once vision was screened by a Vision Champion, a tier coupon was given to the Vision Champion's teacher and a tier was kept by the Vision Champion. If someone needed a referral, a tier coupon was given to them for presentation to the optometrist when they visited Bariadi Vision Centre which was the only Public Vision Centre in the district and situated in the centre of the town which basically services an area within $5 \mathrm{~km}$ radius from its location.

The eye health screening and the eye health promotion were conducted over a 3-month period. Each week, a research supervisor visited the schools and eye centre to do regular follow-up. Three months after the screening and health education efforts of the project, the research supervisor visited the schools to collect the records of the number of children screened, referred and those who attended the Vision Centre. The data were collected from 01 August 2014 to 01 February 2015.

One month before the Vision Champion training, a knowledge and practice survey was undertaken to assess the community's level of understanding about eye health (Phase 1, P1). A precoded and validated questionnaire containing close-ended questions was designed to collect the data. The English questionnaire was translated into Kiswahili to elicit responses from respondents. There were four questions regarding knowledge, six questions regarding awareness and five questions regarding practice of eye health in the questionnaire. The questions on knowledge, awareness and practice of eye health were drafted in accordance with the messages we intend to impart to the community.

The sample used in the survey consisted of one member from the Vision Champion's household and a random selection of one household member from each adjacent household from the Vision Champion's household. Two hundred households were selected and 1200 participants were enrolled in the study. Those included were people who were older than 18 years and resided permanently at the household for more than 6 months. A post-intervention knowledge and practice survey was repeated to determine whether there was a change in the knowledge and practice of eye health in the community (Phase 2, P2).

As the aim of the intervention is to have a snowballing effect of the message being passed on from the Vision Champions to the peers and then to their families, we decided not to follow up the same individuals in the household before and after the intervention, but another member of the household instead. We also foresaw that if the same individual is to be interviewed before and after the intervention, it will be a big possibility that great effort will be put on this particular individual to ensure he or she improves in his or her knowledge and practice, thus creating possible biases.

Before the pilot study, the draft questionnaire (consisting of 21 items) was validated by a panel of experts to ensure simplicity, consistency, completeness, logical sequences and that the question structure was appropriate. Thirty questionnaires were then piloted in a site which was not part of the study sites. The items in the questionnaires were reduced from 21 to 15 as six items elicited very high positive response $(>80 \%)$. The sample population involved all ages and gender groups.

\section{Data analysis}

We designed a recording form to capture the activities of the Vision Champions, which includes:

- the number of people with whom they shared their eye health messages

- the number of people who were screened

- the number of people who were identified and referred after failing vision screening

- information collected from the referral eye clinic to determine those who went for follow-up and their management.

A minimum of $5 \%$ change in pre- and post-intervention was considered significant. This was determined during the pilot study where we traced the change of knowledge and attitude 1 month after intervention. The range of change was 5.7\% $9.3 \%$ for knowledge and $6.2 \%-8.2 \%$ for practice. We assume that the change will be lower in the actual study as the intervention was longer (retention of knowledge may be lower if follow-up time is longer). Hence, a 5\% significance change was adopted.

\section{Ethical considerations}

Informed consent was obtained from Vision Champion's parents and assent from Vision Champions, requesting permission to engage the children in the study. All necessary information was explained to them before obtaining the parents' consents and the children's assents. Children were informed that if there was any incident or suspected incident of exploitation, they could report to our Bariadi Vision Centre Manager, Research Coordinator and our principal investigator. We also obtained informed consent from the participants before the knowledge and attitude survey was conducted. Ethical clearance was obtained from the National Institute for Medical Research, Tanzania. The study adhered to the guidelines provided by the Declaration of Helsinki whereby study includes human subjects.

\section{Results}

The Vision Champions shared their eye health messages with 6311 people. On average, each Vision Champion shared their messages with 53 people (range 30-73 people per Vision Champion). The Vision Champions screened the vision of 
7575 people and referred 2433 people for further care. Out of those who were screened, 5746 (76.4\%) were peers (children), while the rest $(23.6 \%)$ were either family members or neighbours.

There were 460 people (19\%) who went for follow-up management during the first 3 months. After a reminder was given to them, an additional 219 people (28\%) went for followup. Of the people who went for follow-up care, 338 people (50\%) have received spectacles, out whom 189 (56\%) were adults and the rest were children (44\%). There were 106 people who had cataract; 61 went for follow-up and 23 people consented and underwent cataract surgery. The number of patients who visited the Vision Centre had increased from 120 patients per month to 600 patients per month (an increase of $417 \%$ ).

In terms of gender, female Vision Champions shared slightly more eye health messages to community members (male:female 48.9\%:51.1\%) and conducted more vision screening than male Vision Champions (male:female 46.5\%:53.5\%). Female Vision Champions also referred more patients for further eye health management compared to male Vision Champions (male:female 46.1\%:53.9\%). However, the ratio of people who went for eye health management, whether they were referred by a male or female Vision Champion, was almost the same (male:female 1.06:1).

We conducted the knowledge and practice survey on 519 people before and 532 people after the start of the Vision Champion project. The demographic profiles of the participants in Phase 1 (P1) and Phase 2 (P2) are shown in Table 1. There were more people who had at least primary school education in Phase 2 compared to Phase 1 (P2 = 67.1\% vs. P1 = 66.3\%) and more men had at least primary school education.

It was observed that the community became more aware that using eye ointment not prescribed by doctors $(\mathrm{P} 1=58.96 \%$ vs. $\mathrm{P} 2=72.75 \%)$ and cataract $(\mathrm{P} 1=73.57 \%$ vs. $\mathrm{P} 2=82.75 \%)$ can both lead to blindness. While the community were more aware that they should not use other medicine in stock, less people responded that they should see the doctor if a foreign body enters the eye(s) $(\mathrm{P} 1=88.91 \%$ vs. $\mathrm{P} 2=71.96 \%)$. The community were more aware that they should not administer eye drops in stock (P1 $=44.18 \%$ vs. $\mathrm{P} 2=61.37 \%)$ or received from a friend or relative $(\mathrm{P} 1=53.23 \%$ vs. $\mathrm{P} 2=72.35 \%)$ if their eyes are red and painful. The details are provided in Table 2.

\section{Discussion}

The number of people reached by the Vision Champions in terms of sharing eye health messages and vision screening was high because the community found the eye health education material appealing and easy to understand. It attracted the attention of their family and peers. However, the follow-up rate was low $(28 \%)$ because according to the local belief, they were sceptical that the services provided were linked with a cult group who is recruiting followers through outreach activities. This misconception about eye care and factors such as low education level and poverty requires health education among the community to address the barriers of cultural beliefs or scepticism about accessing eye care. Furthermore, the rate of follow-up (28\%) might be higher if a respected adult or teacher made the referrals as a child may not have the same credibility as a respected adult in the community and this aspect requires further research.

The results showed that children have the potential to effectively share eye health messages and conduct simple vision screening for their families and peers. However, more effort is needed to sensitise the community to improve the follow-up rate. There is a need to develop checks and balances to ensure that children are only spreading the message in their immediate environment and are not potentially exposed to strangers, which may increase the risk of child abuse and possibly create security issues.

Overall, the community's eye health knowledge improved (> 5\%) 3 months following the Vision Champions' effort in sharing the eye health messages. Even though there was no similar study conducted in the eye care field, evidence from other health promotion interventions shows interesting

TABLE 1: Demographic profiles of participants in Phases 1 and 2.

\begin{tabular}{|c|c|c|c|c|}
\hline \multirow[t]{2}{*}{ Demography } & \multicolumn{2}{|c|}{ Phase 1} & \multicolumn{2}{|c|}{ Phase 2} \\
\hline & Number & $\%$ & Number & $\%$ \\
\hline \multicolumn{5}{|l|}{ Sex } \\
\hline Male & 211 & 40.7 & 228 & 42.9 \\
\hline Female & 308 & 59.3 & 304 & 57.1 \\
\hline \multicolumn{5}{|l|}{ Age } \\
\hline $15-24$ & 99 & 19.1 & 117 & 22.0 \\
\hline $25-34$ & 133 & 25.6 & 152 & 28.6 \\
\hline $35-44$ & 112 & 21.6 & 126 & 23.7 \\
\hline $45-54$ & 100 & 19.3 & 74 & 13.9 \\
\hline $55-64$ & 31 & 6.0 & 32 & 6.0 \\
\hline $65-74$ & 26 & 5.0 & 20 & 3.8 \\
\hline$>74$ & 18 & 3.4 & 11 & 2.1 \\
\hline \multicolumn{5}{|l|}{ Education } \\
\hline No schooling & 117 & 22.5 & 82 & 15.4 \\
\hline Primary school incomplete & 58 & 11.2 & 93 & 17.5 \\
\hline Primary school complete & 211 & 40.7 & 247 & 46.4 \\
\hline Secondary school incomplete & 11 & 2.1 & 22 & 4.1 \\
\hline Secondary school complete & 71 & 13.7 & 48 & 9.0 \\
\hline Higher education complete & 39 & 7.5 & 36 & 6.8 \\
\hline University or College complete & 1 & 0.2 & 4 & 0.8 \\
\hline Do not know & 1 & 0.2 & 0 & 0.0 \\
\hline Refused to provide information & 10 & 1.9 & 0 & 0.0 \\
\hline \multicolumn{5}{|l|}{ Occupation } \\
\hline Professional & 71 & 13.7 & 81 & 15.2 \\
\hline Agriculture & 333 & 64.2 & 340 & 64.0 \\
\hline Construction & 13 & 2.5 & 8 & 1.5 \\
\hline Home duties & 24 & 4.6 & 31 & 5.8 \\
\hline Clerical & 11 & 2.1 & 15 & 2.8 \\
\hline Student & 8 & 1.5 & 8 & 1.5 \\
\hline Retired & 4 & 0.8 & 1 & 0.2 \\
\hline Unemployed & 54 & 10.4 & 48 & 9.0 \\
\hline Refused to provide information & 1 & 0.2 & - & - \\
\hline Total & 519 & 100 & 532 & 100 \\
\hline
\end{tabular}


TABLE 2: Change in knowledge, attitude and practice before and after intervention.

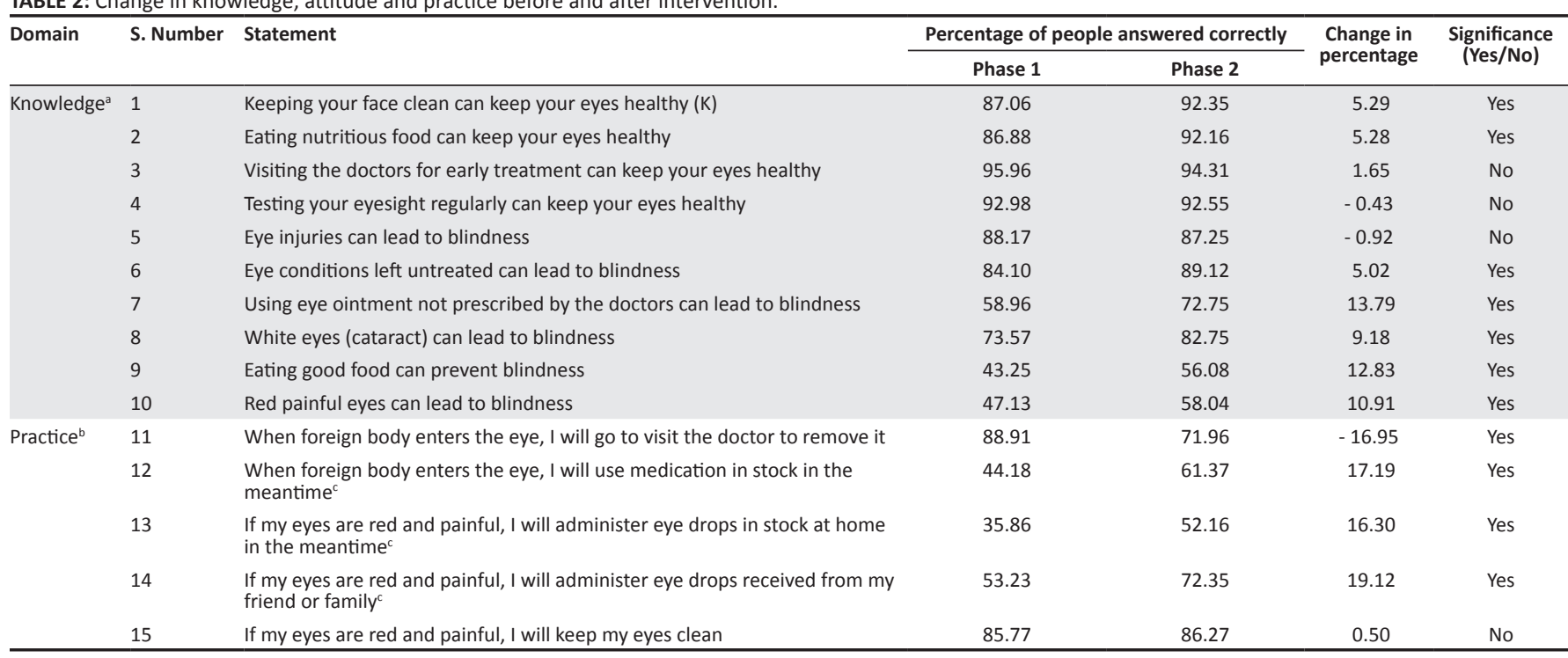

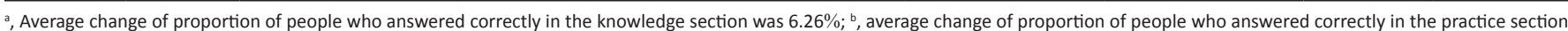
was $7.3 \%$; ${ }^{c}$, a positive change indicates improved eye health practice.

results. Macri and Tsiantis found that in their 13 months' health promotion among smoking youth, there was a negative effect on knowledge in their peer-led programme. ${ }^{18}$ However, the authors attributed that to the high attrition rate $(40 \%)$.

Best et al. however found similar positive results in their testicular cancer education programme compared to our study. They found that the intervention led to an increase in knowledge and in their practice in screening of testicular cancer at 6 months follow-up. They found that peer-led groups have higher knowledge about steps involved in testicular self-examination. ${ }^{19}$ However, this was in an adult population and may have limited relevance to Vision Champions. Onyango-Ouma et al. investigated the potential of schoolchildren as health change agents in rural western Kenya in a prospective study over a 4-month period and found significant improvement in the knowledge regarding malaria, diarrhoea and hygiene among recipient groups. ${ }^{20}$ Similar findings were also reported by Ayorinde et al. in Southwest Nigeria, where they studied the usefulness of the child-to-child approach in improving uptake of eye care services to difficult-to-reach rural communities. They found that there was an overall significant improvement in knowledge. ${ }^{21}$

Eye health practices such as having regular eye testing, seeking early treatment to maintain healthy eyesight and seeking medical care if a foreign body enters the eye(s) had no significant improvement and there was even negative change. McAlister et al. ${ }^{22}$ also reported similar impact on practices towards smoking following the School Health Curriculum Project or 'Berkeley Project'. It was found that significantly fewer students reported smoking in the last 1 week than at 3 months follow-up. It was said that peers have the ability to influence the entire social atmosphere regarding smoking. This was also shown by Elder et al. in their health education initiatives on smoking and they hypothesised that older peers would serve as positive role models who would also be able to develop a better rapport with younger peers. They also found $8.5 \%$ less tobacco use in the last 1 month after 3 years of intervention. ${ }^{23}$ Similar results were also observed in North Kareila by Vartiainen et al. in the peer-led programme. It was shown that the peer-led programme had $49 \%$ less smokers compared to the teacher-led programme. ${ }^{24}$ In a 5 -week study in rural Zambia to explore the potential of schoolchildren as change agents in the context of school Water Sanitation and Hygiene (WASH), it was also found that most pupils reported safe sanitation and hygiene behaviours at school and, because of a high perceived risk of disease, wanted to practice these behaviours at home. ${ }^{25}$

It is important to make the community aware of the need to maintain good hygiene when there are eye infections and that eye injuries can lead to blindness as these are causes of vision impairment that can be preventable. A similar finding was also shown by Orpinas et al. who found significant improvement in awareness and reduction in experience of aggressive behaviours in a school which had a peer-led health education initiative. ${ }^{26}$ This was also observed in the Triple-A programme by Gibson et al. which was focused on peer-led asthma education, where the study demonstrated that peer-led asthma education is feasible in the school setting. ${ }^{27}$

\section{Limitations and recommendations}

Some eye health-seeking practices which were found to have no significant improvement and even negative change indicates that change may need a longer time to take effect in the community as it needs a multidisciplinary approach or the message was not appropriate and needs to be reconsidered. Furthermore, Vision Champions can only address some of the reported barriers, such as awareness and knowledge; however, they cannot have any impact on the distance to services or on the cost of eye care. 
It is important to make the community aware of the need to keep their eyes clean when there are eye infections and that eye injuries can lead to blindness as these are causes of vision impairment that are preventable. We recommend that the cartoon booklet be improved to address the gaps identified in the study. A longer follow-up period (more than 3 months) is also recommended to detect any meaningful change in eye health practices following the Vision Champion initiative.

Another limitation of this study is that we did not assess the accuracy of the referrals but rather the volume and response of the subjects. Further investigation on sensitivity and specificity of the screenings by the Vision Champions is also recommended.

\section{Conclusion}

Overall, the community's eye health knowledge improved (> 5\%) 3 months following the Vision Champions' efforts in sharing their eye health messages.

The results showed that children have the potential to effectively share eye health messages and conduct simple vision screening for their families and peers. However, more effort is needed to sensitise the community to improve the referral or follow-up rate.

\section{Acknowledgements}

The authors thank the Lions Clubs International Foundation's SightFirst grant for its funding support. They also thank $\mathrm{Mr}$ Eliabu Mbuguma and Mr Tabu Rocket for their commitment in the implementation of the study.

\section{Competing interests}

The authors declare that they have no financial or personal relationships that may have inappropriately influenced them in writing this article.

\section{Authors' contributions}

V.F.C. was the principal investigator of the study. He was involved in the design of the study, which includes writing up the proposal, designing the tool and data analysis. He contributed to the overall write up of the manuscript. H.M. was the co-investigator of the study. He was involved in the design of the study, focusing on the writing up of the proposal, designing of the tool, implementation of the study and data management and data analysis of the study. $\mathrm{He}$ contributed $60 \%$ to the write up of the study. E.M. was the co-investigator of the study. He was involved in the design of the study, which includes writing up the proposal, designing the tool and data collection. He contributed $20 \%$ to the write up of the study. K.S.N. was the co-investigator of the study. He was involved in the design of the study, which includes writing up the proposal and designing the tool. He contributed $50 \%$ to the write up of the study.

\section{References}

1. Society for International Development. State of East Africa Report 2012: Deepening Integration, Intensifying Challenges. Nairobi: Society for Internationa Development (SID); 2012 [cited 2013 Jan. 31]. Available from http://www.sidint. net/docs/SoEAR2012_final.pdf

2. Resnikoff S, Pascolini D, Mariotti SP, Pokharel GP. Global magnitude of visual impairment caused by uncorrected refractive errors in 2004 . Bull World Health Organ. 2008;86:63-70. https://doi.org/10.2471/BLT.07.041210

3. Kovai V, Krishnaiah S, Shamanna BR, Thomas R, Rao GN. Barriers to accessing eye care services among visually impaired populations in rural Andhra Indian J Ophthalmol. 2007;55(5):365-371. https://doi.org/10.4103/0301-4738.33823

4. Nirmalan PK, Katz J, Robin AL, Krishnadas R, Ramakrishnan R, Thulasiraj RD, Tielsch J. Utilisation of eye care services in rural south India: The Aravind Comprehensive Eye Survey. Br J Ophthalmol. 2004;88(10):1237-1241. https:// doi.org/10.1136/bjo.2004.042606

5. Brilliant GE, Lepkowski JM, Zurita B, Thulasiraj RD. Social determinants of cataract surgery utilization in south India. The Operations Research Group. Arch Ophthalmol. 1991;109(4):584-589. https://doi.org/10.1001/archopht.1991.01080040152048

6. Dickey $H$, Ikenwilo $D$, Norwood $P$, Watson V, Zangelidis A. Utilisation of eye-care services: The effect of Scotland's free eye examination policy. Health Policy 2012;108(2-3):286-293. https://doi.org/10.1016/j.healthpol.2012.09.006

7. Sandhu S, Van Wijngaarden P, Nguyen DQ, O'Hare F, Sandhu N, Wang JJ, Crowston JG. Socio-demographic factors and utilisation of eye care services: Is there an association Socio-demographic factors and utilisation of eye care services: Is there an association
with patients presenting to a tertiary referral hospital in acute angle closure? Clin Exp with patients presenting to a tertiary referral hospital in acute angle closure? Clin Exp
Ophthalmol. 2013;41:56-62. https://doi.org/10.1111/j.1442-9071.2012.02820.x

8. Majeed M, Williams C, Northstone K, Ben-Shlomo Y. Are there inequities in the utilisation of childhood eye-care services in relation to socio-economic status? Evidence from the ALSPAC cohort. Br J Ophthalmol. 2008;92(7):965-969. https:// doi.org/10.1136/bjo.2007.134841

9. Dawodu OA, Okogie OH, Ukponmwan CO. Pattern of utilisation of eye care services in Benin City, Nigeria. Nigerian Postgrad Med J. 2006;13(4):323-325.

10. Ndegwa LK, Karimurio J, Okelo RO, Adala HS. Barriers to utilisation of eye care services in Kibera slums of Nairobi. East Afr Med J. 2005;82(10):506-508.

11. Keeffe JE, Weih LM, McCarty CA, Taylor HR. Utilisation of eye care services by urban and rural Australians. Br J Ophthalmol. 2002;86(1):24-27. https://doi. org/10.1136/bjo.86.1.24

12. Awobem JF, Cassels-Brown A, Buchan JC, Hughes KA. Exploring glaucoma awareness and the utilization of primary eye care services: Community perceived barriers among elderly African Caribbeans in Chapeltown, Leeds. Eye. 2009; 23(1):243. https://doi.org/10.1038/eye.2008.42

13. Marmot M. Social determinants and the health of Indigenous Australians. Med Aust. 2011;194(10):512-513.

14. Carson B, Dunbar T, Chenhall RD, Bailie R. Social determinants of indigenous health. New South Wales, Australia: Allen \& Unwin; 2007.

15. Watson C. Why warriors lie down and die: Towards an understanding of why the Aboriginal people of Arnhem Land face the greatest crisis in health and education
since European contact: R. Trudgen. Aust J Rural Health. 2001;9(3):141-142. since European contact: R. Trudgen. Aust J Rura
https://doi.org/10.1046/j.1440-1584.2001.00375.x

16. Gruen RL, Bailie RS, d'Abbs PH, O'Rourke IC, O'Brien MM, Verma N. Improving access to specialist care for remote Aboriginal communities: Evaluation of a specialist outreach service. Med J Aust. 2001;174(10):507-511.

17. Carson PJ. Providing specialist services in Australia across barriers of distance and culture. World J Surg. 2009;33(8):1562-1567. https://doi.org/10.1007/s00268009-0088-1

18. Macri I, Tsiantis J. Effects of a peer led intervention program on smoking prevention: A case example in Greece. Int Q Comm Health Educ. 1997-1998;17:297-308. https://doi.org/10.2190/1QB8-4UEQ-DODC-1KAF

19. Best DL, Davis SW, Vaz RM, Kaiser M. Testicular cancer education: A comparison of teaching methods. Am J Health Behav. 1996;20(4):229-241.

20. Onyango-Ouma W, Aagaard-Hansen J, Jensen BB. The potential of schoolchildren as health change agents in rural western Kenya. Soc Sci Med. 2005;61(8):17111722. https://doi.org/10.1016/j.socscimed.2005.03.041

21. Ayorinde OO, Murthy GV, Akinyemi OO. Is the child-to-child approach useful in improving uptake of eye care services in difficult-to-reach rural communities? Experience from southwest Nigeria. Ann Ib Postgrad Med. 2016;14(2):65-73.

22. McAlister A, Perry C, Killen J, Slinkard LA, Maccoby N. Pilot study of smoking, alcohol and drug abuse prevention. Am J Public Health. 1980;70(7):719-721. https://doi.org/10.2105/AJPH.70.7.719

23. Elder JP, Woodruff SI, Sallis JF, De Moor C, Edwards C, Wildey MB. Effects of health facilitator performance and attendance at training sessions on the acquisition of
tobacco refusal skills among multiethnic, high-risk adolescents. Health Educ Res. tobacco refusal skills among multiethnic, high-risk adoles
1994;9(2):225-233. https://doi.org/10.1093/her/9.2.225

24. Vartiainen E, Pallonen U, McAlister A, Koskela K, Puska P. Four-year follow-up results of the smoking prevention program in the North Karelia Youth Project. Prev Med. 1986;15(6):692-698. https://doi.org/10.1016/0091-7435(86)90074-5

25. USAID. Exploring the potential of schoolchildren as change agents in the context of school WASH in rural Zambia [homepage on the Internet]. July 2014 [cited 2017 Sep 18]. Available from: http://pdf.usaid.gov/pdf docs/PA00KKKC.pdf

26. Orpinas $P$, Parcel GS, McAlister A, Frankowski R. Violence prevention in middle schools: A pilot evaluation. J Adolescent Health. 1995;17:360-371. https://doi. org/10.1016/1054-139X(95)00194-W

27. Gibson PG, Shah S, Mamoon HA. Peer-led asthma education for adolescents: Impact evaluation. J Adolescent Health. 1998;22:66-72. https://doi.org/10.1016/ S1054-139X(97)00203-6 